\title{
Extracompartmental Tumor
}

National Cancer Institute

\section{Source}

National Cancer Institute. Extracompartmental Tumor. NCI Thesaurus. Code C140265.

Bone tumors extend beyond the bone cortex. 